\title{
Micropropagation and germplasm conservation of four chickpea (Cicer arietinum L.) genotypes
}

\author{
Salem S. Alghamdi ${ }^{1}$, Yaser Hassan Dewir ${ }^{1,2^{*}}$, Muhammad Altaf Khan ${ }^{1}$, Hussein Migdadi ${ }^{1}$, \\ Ehab H. EL-Harty ${ }^{1}$, Abdulhakim A. Aldubai ${ }^{1,3}$, and Ahmed A. Al-Aizari ${ }^{1}$
}

\begin{abstract}
${ }^{1}$ King Saud University, College of Food and Agriculture Sciences, Plant Production Department, P.O. Box 2460, Riyadh 11451, Saudi Arabia.

${ }^{2}$ Kafrelsheikh University, Faculty of Agriculture, Department of Horticulture, Kafr El-Sheikh 33516, Egypt.

"Corresponding author (ydewir@hotmail.com; ydewir@ksu.edu.sa).

${ }^{3}$ Agriculture Research and Extension Authority, Sana'a 87148, Yemen.
\end{abstract}

Received: 14 April 2020; Accepted: 21 June 2020; doi:10.4067/S0718-58392020000400487

\begin{abstract}
Genetic improvement of chickpea (Cicer arietinum L.), a recalcitrant crop, has been largely restricted owing to a lack of efficient regeneration methods. In this study, four chickpea genotypes (Giza 4, Giza 88, Giza 195, and Giza 531) were efficiently micropropagated using embryo axes and synthetic seeds developed using an encapsulation technique. Multiple shoots grew from embryo explants using 2 and $4 \mathrm{mg} \mathrm{L}^{-1}$ benzylaminopurine (BAP). The number of shoots for Giza 195 explants using 4 and $6 \mathrm{mg} \mathrm{L}^{-1}$ BAP were 5.8 and 6.2, respectively. The elongated shoots were transferred to two indole3-butyric acid (IBA) concentrations (50 and $100 \mathrm{mmol} \mathrm{L}^{-1}$ ) for root induction. A high rooting percentage (67\%-100\%) followed by successful acclimatization (70\%-75\%) was obtained for shoots dipped in 50 mmol L-1 IBA and cultured into an MS liquid medium. Apical buds from in vitro shoots were encapsulated in sodium alginate along with calcium chloride to produce synthetic seeds, which were successfully stored at $4{ }^{\circ} \mathrm{C}$ for 5 mo. Giza 195 and Giza 531 were better conserved than Giza 4 and Giza 88, with 70\%-75\% regrowth and recovery rates. These results confirmed an efficient regeneration protocol and synthetic seed production, which could be utilized for genetic transformations and crop improvement.
\end{abstract}

Key words: Embryo, recalcitrant crops, regeneration, rooting, synthetic seeds.

\section{INTRODUCTION}

Chickpea (Cicer arietinum L.; Fabaceae) is an annual, self-pollinating, diploid $(2 n=2 \mathrm{x}=16)$ plants with short life cycles of approximately 3-4 mo. Chickpea is considered the world's second most important pulse crop after beans and is mainly grown in arid and semi-arid regions of the world (FAOSTAT Database, 2018). According to FAO statistics for Saudi Arabia, an average of $64686 \mathrm{t}$ ( $\$ 64$ million) of chickpea was imported in 2017. Chickpea is a good source of protein $(12.4 \%-31.5 \%)$, carbohydrate $(48.2 \%-67.6 \%)$, fat (6\%), and nutritionally important minerals. Legumes and chickpea are the best sources of hypocholesterolemic agents, followed by black and green grams. An efficient and reproducible plant regeneration system is prerequisite for genetic engineering of chickpea crop. Several in vitro regeneration protocols have been reported for chickpea (Chauhan et al., 2003; Jayanand et al., 2003; Aasim et al., 2013; Al-Tanbouz and AbuQaoud, 2016). However, low success rates for the rooting and acclimatization of regenerated plants were a major hurdle. Reports by various scientists and research groups indicated that direct organogenesis and establishment of plantlets from various chickpea explants is feasible (Polisetty et al., 1997; Chauhan et al., 2003; Jayanand et al., 2003; Mirakabad et al., 2010). Moreover, development of chickpea plantlets from different explants has been achieved using direct somatic embryogenesis and callus (Naz et al., 2008; Mirakabad et al., 2010). However, low multiple shoot induction and poor rooting responses have been observed (Huda et al., 2003; Jayanand et al., 2003; Naz et al., 2008; Banu et al., 2011; Parveen et al., 2012; Al-Tanbouz and Abu-Qaoud, 2016). In general, two major hurdles that limit in vitro regeneration of 
chickpea are the induction and development of strong root systems, and the establishment of in vitro plantlets raised in pots (Anwar et al., 2010). Therefore, there has always been a need for the establishment of an in vitro plant regeneration system for efficient shoot and root induction.

Development of synthetic seeds offers an efficient means for the mass propagation of crop plants. This technology uses encapsulated propagules of many plant species and has become a potentially cost-effective clonal propagation system. In vitro techniques have been widely used for the conservation and propagation of species where traditional multiplication and storage techniques are challenging (Ozudogru et al., 2011). Synthetic seeds are typically encapsulated somatic embryos or vegetative plant parts such as shoots, axillary tissues, or any other micropropagules, which can be used as seed and grown into a plant under in vitro or vivo conditions (Rihan et al., 2017). The advantages of this technology include genetically identical plants, virus-free germplasm, low costs of production, and long-term storage capabilities (Ghosh and Sen, 1994). The synthetic seed technology has been developed in several economically important plant species, such as forage legumes, industrially important crops, vegetable crops, fruit crops, cereals, ornamental plants, and medicinal plants (Reddy et al., 2012). Successful plant regeneration from synthetic seeds has been reported in several plant species (Rihan et al., 2017). However, in vitro conservation via encapsulation should be optimized for each species. To the best of our knowledge, there are no reports regarding in vitro encapsulation of chickpea; therefore, the present study aimed to optimize factors affecting the production of artificial seeds. In view of the enormous importance of this nutritive pulse crop, the present study was designed to develop a reproducible, efficient in vitro plant regeneration system along with synthetic seed production.

\section{MATERIALS AND METHODS}

\section{Plant material and surface disinfection}

Chickpea (Cicer arietinum L.) seeds of three 'Kabuli' genotypes (Giza 4, Giza 195, Giza 531) and one 'Desi' genotype (Giza 88) were obtained from Agricultural Research Center, Giza, Egypt. The seeds were washed with tap water, surface sterilized with $70 \%(\mathrm{v} / \mathrm{v})$ ethanol for $10 \mathrm{~s}$, soaked in a $20 \%(\mathrm{v} / \mathrm{v}) 5.2 \%$ sodium hypochlorite solution containing 2-3 drops Tween 20 (polyoxyethylene sorbitan monolaurate) for $15 \mathrm{~min}$, which was followed by rinsing three times with sterile distilled water. The seeds were soaked in sterile distilled water for $24 \mathrm{~h}$.

\section{Axillary shoot multiplication}

An embryo axis with a cotyledonary part attached was excised (Figure 1A) and inoculated to Magenta culture vessels (4 embryos per vessel) that contained $60 \mathrm{~mL}$ MS medium (Murashige and Skoog, 1962) supplemented with different concentrations of benzylaminopurine (BAP) $\left(0,2,4\right.$, and $\left.6 \mathrm{mg} \mathrm{L}^{-1}\right)$ for $15 \mathrm{~d}$. The differentiated axillary shoots were subcultured on MS medium without plant growth regulators (PGRs) for $15 \mathrm{~d}$. The $\mathrm{pH}$ of all mediums was adjusted to 5.8 before autoclaving $\left(121^{\circ} \mathrm{C}\right.$ and $1.2 \mathrm{~kg} \mathrm{~cm}^{-2}$ for $\left.15 \mathrm{~min}\right)$. The cultures were incubated at $25 \pm 2{ }^{\circ} \mathrm{C}$ under a $16: 8 \mathrm{~h}$ photoperiod with a $35 \mu \mathrm{mol} \mathrm{m} \mathrm{m}^{-2} \mathrm{~s}^{-1}$ photosynthetic photon flux density (PPFD) provided by cool white fluorescent tubes; PPFD was measured using a luminous intensity meter (Testo 545; Testo, Melrose, Massachusetts, USA). After $30 \mathrm{~d}$ incubation, percentage of germinated embryo, number of shoots per germinated embryo, and fresh weights per explants were recorded.

\section{In vitro rooting}

In vitro regenerated shoots $(2-3 \mathrm{~cm})$ at the optimal BAP concentration for each genotype (Table 1) were used as plant material for rooting experiments. In the first experiment, different concentrations of indole-3-butyric acid (IBA) and culture types were tested. The bases of the Giza 4 shoots were dipped for $1 \mathrm{~s}$ into 50 and $100 \mathrm{mM} \mathrm{L}^{-1}$ IBA filter sterilized solutions and cultured in half strength MS basal salts liquid and gelled mediums supplemented with $2 \%(\mathrm{w} / \mathrm{v})$ sucrose. The gelled medium was solidified with $0.7 \%$ (w/v) agar with a filter paper bridge that was used to hold the shoots above the liquid medium surface. Sterilized peat moss was also tested as a growing substrate for in vitro rooting of chickpea. The peat moss was moistened with $1 / 2$ MS basal salts without sucrose. In the second experiment, the in vitro shoots of the four genotypes were cultured in a half strength MS basal salts liquid medium supplemented with $50 \mathrm{mM} \mathrm{L}^{-1} \mathrm{IBA}$ and 20 or $40 \mathrm{~g} \mathrm{~L} \mathrm{~L}^{-1}$ sucrose concentrations. All cultures were maintained at $25^{\circ} \mathrm{C}$ under a $16: 8 \mathrm{~h}$ photoperiod of $50 \mu \mathrm{mol} \mathrm{m}^{-2} \mathrm{~s}^{-1}$ PPFD. After $3 \mathrm{wk}$, the rooting success (rooting percentage, root length, and number of roots per explant) and fresh weight were recorded. 
Figure 1. Micropropagation of chickpea. A. Excised embryo axis explants used for culture initiation. B. Axillary shoot clusters after 15 d culture on benzyladenine-enriched Murashige and Skoog's (MS) medium followed by 15 d culture on MS medium without plant growth regulators (PGR). C. Elongation of chickpea shoots on MS medium without PGR. D. Rooting of chickpea shoots after 2 wk on liquid and gelled MS medium using dipping in indole-3-butyric acid at 50 and $100 \mathrm{mmol} \mathrm{L}^{-1}$ for $1 \mathrm{~s}$. E. Rooting of chickpea shoots after 2 wk culture in sterile peat moss. F-G. Symptoms of shoot tip necrosis and yellowing of shoots at $100 \mathrm{mmol} \mathrm{L}^{-1}$ IBA. H. Healthy rooted chickpea shoots. I-J. Acclimatized chickpea plantlets.

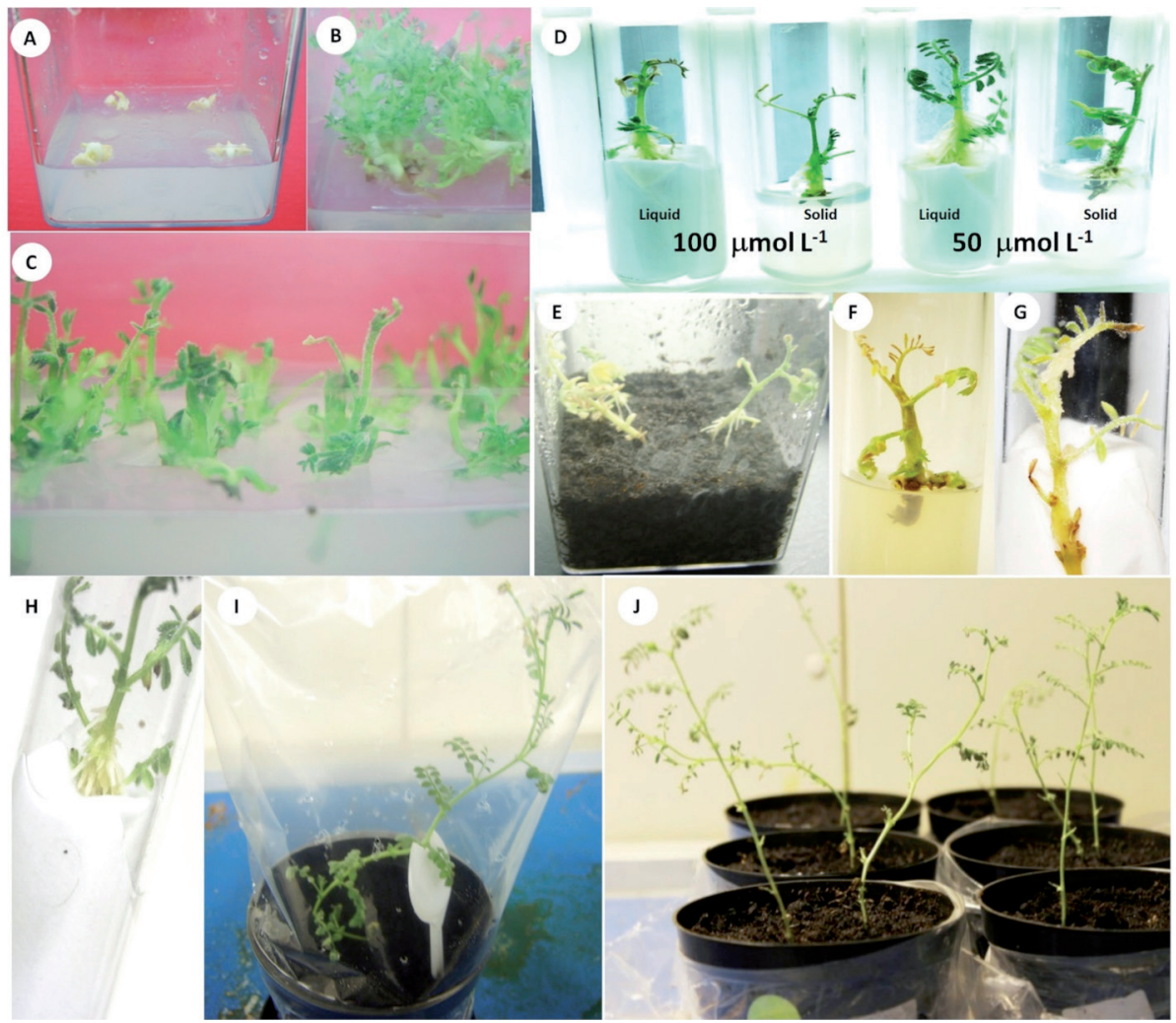

\section{Acclimatization of chickpea plantlets}

Chickpea rooted axillary shoots which were regenerated using embryo axis explants were carefully washed with tap water and transferred into plastic pots filled with equal volumes of a sterile mixture of perlite and peat moss. The potted plants were incubated for $30 \mathrm{~d}$ at $25 \pm 2{ }^{\circ} \mathrm{C}$ and $50 \%-60 \%$ relative humidity under a $16: 8 \mathrm{~h}$ photoperiod of $70 \mu \mathrm{mol} \mathrm{m}^{-2} \mathrm{~s}^{-1} \mathrm{PPFD}$ provided by white fluorescent lamps in a growth chamber (Model KBWF 720; Binder, Tuttlingen, Germany). The pots were covered with a transparent polyethylene sheet for the first $10 \mathrm{~d}$. The plantlets were regularly irrigated using a nutrient solution containing half-strength MS basal salts. Plantlet survival was evaluated at $30 \mathrm{~d}$.

\section{Development of synthetic seeds}

For slow growth storage of the chickpea synthetic seeds, the apical buds were excised from in vitro shoot cultures. For synthetic seed preparation, buds ( $\sim 0.5 \mathrm{~cm}$ long) were suspended in a 1/2 MS media with $3 \%(\mathrm{w} / \mathrm{v})$ sodium alginate (MS free from $\left.\mathrm{Ca}^{2+}\right)$ solution and dropped into a $100 \mathrm{mM}$ calcium chloride $\left(\mathrm{CaCl}_{2}\right)$ solution, with each drop containing one explant as described by Lambardi et al. (2006). The beads were kept for $30 \mathrm{~min}$ at room temperature in a $\mathrm{CaCl}_{2}$ solution $\left(14 \mathrm{~g} \mathrm{~L}^{-1}\right)$ to ensure complete polymerization, collected with a sterile sieve, and washed with sterile distilled water. Beads were transferred to $90 \mathrm{~mm}$ Petri dishes containing $20 \mathrm{~mL} \mathrm{7 \%}$ agar. Synthetic seeds were maintained at $4{ }^{\circ} \mathrm{C}$ in the dark (cold storage) for various period intervals to assess their viability. Synthetic seeds were plated on MS medium in Petri dishes and transferred to standard culture conditions (MS medium supplemented with $1 \mathrm{mg} \mathrm{L}^{-1}$ zeatin) and were checked after $10 \mathrm{~d}$ of re-culturing. Shoot survival were recorded after 1,2,3, and 5 mo preservation to monitor explant survival and re-growth ability. 
Table 1. Effect of benzylaminopurine (BAP) concentration on embryo germination and subsequent shoot multiplication after 15 d culture on MS medium containing BAP followed by 15 d culture on MS medium without plant growth regulators (PGR).

\begin{tabular}{|c|c|c|c|c|c|c|}
\hline \multirow[b]{2}{*}{ Genotype } & \multirow[b]{2}{*}{ BAP Conc. } & \multicolumn{3}{|c|}{$\begin{array}{l}\text { Initial culture on MS medium with different } \\
\text { BAP concentrations for } 15 \mathrm{~d}\end{array}$} & \multicolumn{2}{|c|}{$\begin{array}{l}1^{\text {st }} \text { subculture on MS medium } \\
\text { without PGRs for } 15 \mathrm{~d}\end{array}$} \\
\hline & & $\begin{array}{l}\text { Embryo } \\
\text { germination }\end{array}$ & Shoots & Fresh weight & Shoots & Fresh weight \\
\hline & $\mathrm{mg} \mathrm{L}^{-1}$ & $\%$ & $\mathrm{Nr}$ explant ${ }^{-1}$ & $\mathrm{~g}$ explant $^{-1}$ & $\mathrm{Nr}$ explant ${ }^{-1}$ & g explant ${ }^{-1}$ \\
\hline \multirow[t]{4}{*}{ Giza 4} & 0 & $92 \mathrm{a}$ & $1.6 \mathrm{ef}$ & $0.63 \mathrm{ef}$ & $1.4 \mathrm{~g}$ & $0.27 \mathrm{~h}$ \\
\hline & 2 & $8 f$ & $5.0 \mathrm{a}$ & $0.54 \mathrm{f}$ & 4.0def & $0.75 \mathrm{c}$ \\
\hline & 4 & $33 \mathrm{e}$ & $4.0 \mathrm{bcd}$ & $0.59 \mathrm{f}$ & $3.9 \mathrm{ef}$ & $0.56 \mathrm{efg}$ \\
\hline & 6 & $58 \mathrm{~d}$ & $3.3 \mathrm{~d}$ & $0.76 \mathrm{cdef}$ & $5.6 \mathrm{ab}$ & $1.15 \mathrm{a}$ \\
\hline \multirow[t]{4}{*}{ Giza 88} & 0 & $83 b$ & $2.3 \mathrm{e}$ & 0.89 bcde & $1.0 \mathrm{~g}$ & $0.07 \mathrm{j}$ \\
\hline & 2 & $83 b$ & $4.2 \mathrm{abc}$ & $0.91 \mathrm{bcd}$ & $3.3 \mathrm{f}$ & $0.51 \mathrm{~g}$ \\
\hline & 4 & $75 c$ & $4.3 \mathrm{ab}$ & $0.92 \mathrm{bc}$ & $4.0 \mathrm{def}$ & $0.72 \mathrm{~cd}$ \\
\hline & 6 & $50 \mathrm{~d}$ & $3.3 \mathrm{~cd}$ & $0.77 \mathrm{cdef}$ & $3.7 \mathrm{ef}$ & $0.87 \mathrm{~b}$ \\
\hline \multirow[t]{4}{*}{ Giza 195} & 0 & $67 \mathrm{c}$ & $1.0 \mathrm{f}$ & $0.72 \mathrm{cdef}$ & $1.2 \mathrm{~g}$ & $0.22 \mathrm{hi}$ \\
\hline & 2 & $67 \mathrm{c}$ & $4.5 \mathrm{ab}$ & $0.78 \mathrm{cdef}$ & $5.1 \mathrm{bc}$ & $0.52 \mathrm{~g}$ \\
\hline & 4 & $67 \mathrm{c}$ & $4.7 \mathrm{ab}$ & $0.79 \mathrm{cdef}$ & $5.8 \mathrm{ab}$ & $0.61 \mathrm{defg}$ \\
\hline & 6 & $50 \mathrm{~d}$ & $4.0 \mathrm{bcd}$ & $0.64 \mathrm{def}$ & $6.2 \mathrm{a}$ & $0.66 \mathrm{cdef}$ \\
\hline \multirow[t]{4}{*}{ Giza 531} & 0 & $100 \mathrm{a}$ & $1.7 \mathrm{ef}$ & $0.96 a b c$ & $1.1 \mathrm{~g}$ & $0.14 \mathrm{j}$ \\
\hline & 2 & $100 \mathrm{a}$ & $5.0 \mathrm{a}$ & $1.20 \mathrm{a}$ & 4.1de & $0.54 \mathrm{fg}$ \\
\hline & 4 & $75 \mathrm{c}$ & $4.2 \mathrm{abc}$ & $1.21 \mathrm{a}$ & $4.8 \mathrm{~cd}$ & $0.68 \mathrm{cde}$ \\
\hline & 6 & $83 b$ & $3.9 \mathrm{bcd}$ & $1.07 \mathrm{ab}$ & $4.8 \mathrm{~cd}$ & $0.69 \mathrm{cde}$ \\
\hline \multicolumn{7}{|c|}{ Significance } \\
\hline \multicolumn{2}{|l|}{ Genotype } & $*$ & ns & $*$ & $*$ & $*$ \\
\hline \multicolumn{2}{|c|}{ BAP concentrations } & $*$ & $*$ & ns & $*$ & $*$ \\
\hline \multicolumn{2}{|c|}{ Genotype $\times$ BAP concentrations } & $*$ & $*$ & ns & $*$ & $*$ \\
\hline
\end{tabular}

Values followed by the same letter in the same column are nonsignificantly different according to Tukey's test $(\mathrm{P} \leq 0.05)$.

*Significant at $\mathrm{P} \leq 0.01$; ns: nonsignificant.

\section{Experimental design and statistical analysis}

The experiments were set up using a completely randomized design and replicated twice. Each experiment had three replicates per treatment and each replicate used a culture vessel (Magenta GA-7) containing four explants, rendering 12 explants per treatment. All data were tested with ANOVA and Tukey's range tests using SAS version 9.13 statistical software (SAS Institute, Cary, North Carolina, USA).

\section{RESULTS AND DISCUSSION}

\section{Axillary shoot proliferation using embryo axes}

Significant differences were found among genotypes, BAP concentrations, and their interactions for axillary shoot proliferation and growth after $30 \mathrm{~d}$ culture (Table 1). The highest number of shoots were observed at 2 and $4 \mathrm{mg} \mathrm{L}^{-1} \mathrm{BAP}$ for all tested genotypes. BAP concentration had different effects on the genotypic responses to multiple shoot formation. For instance, $2 \mathrm{mg} \mathrm{L}^{-1}$ was the best for Giza 531, while Giza 195 performed better in the $4 \mathrm{mg}$ treatments. Both Giza 4 and Giza 531 had the highest values and produced five shoots per embryo. BAP enriched mediums tended to produce heavier shoots than the control (BAP free medium). However, significant variations were observed when transferred to cytokinin free media. The lowest number of shoots were observed on controls (medium lacking BAP) and ranged from 1.0 for Giza 195 to 2.3 for Giza 88. The results clearly indicated the importance of BAP for multiple shoot formation from chickpea embryo explants. The results also indicated the importance of subculturing on hormone free medium when used as a secondary medium for improving multiple shoot formation (Figure 1B) and elongation (Figure 1C).

In vitro propagation of chickpea has been achieved via various regeneration pathways such as direct organogenesis (Sunil et al., 2015), indirect organogenesis (Minaei Chenar et al., 2016), and somatic embryogenesis (Murthy et al., 1996; Naz et al., 2008). Direct organogenesis is a favored regeneration approach due to the rapid growth rate and high rates of genetic stability. The use of embryo explants has proved effective for shoot regeneration of chickpea (Yadav and Singh, 2012; Ali et al., 2017; Amer et al., 2019; Raghavendra et al., 2019). Additionally, the presence of cotyledon 
parts attached to embryo explants is supportive for multiple shoot production in chickpea (Singh et al., 2002; Ali et al., 2017; Amer et al., 2019). The results of the present study show that direct multiplication of chickpea using embryos was more efficient than regeneration via callus formation. According to Huda et al. (2003), a maximum frequency of chickpea shoot formation (40) with 2.5 shoots per callus was obtained on MS medium fortified with $2.0 \mathrm{mg} \mathrm{L}^{-1} \mathrm{BAP}$ and $0.5 \mathrm{mg} \mathrm{L}^{-1} \mathrm{NAA}$. Mirakabad et al. (2010) also reported a maximum frequency of chickpea shoot formation (52.8\%) with 1.72 shoots per callus in MS medium fortified with $2.0 \mathrm{mg} \mathrm{L}^{-1} \mathrm{BAP}$ and $0.125 \mathrm{mg} \mathrm{L}^{-1} \mathrm{IBA}$. Yadav and Singh (2012) reported varied regeneration (10\%-83\%) of 'Kabuli' chickpea depending on genotype, explant used and culture media. BAP has proved effective as a cytokinin for chickpea shoot organogenesis (Yousefiara et al., 2008; Sunil et al., 2015; Ali et al., 2017; Amer et al., 2019). However, the optimal BAP concentration is genotype-dependent. In the present study, shoot regeneration and fresh weight were significantly influenced by genotype, BAP concentration, and their interaction. Genotypic differences were clearly noticed in our experiment. The percentage of responding embryos ranged from 8\%$100 \%$, depending on the genotype and BAP concentration.

\section{Rooting by dipping in IBA and placement in three culture types}

The highest rooting responses, rooting percentage (90\%), number of roots $(27.5)$, root length $(1.3 \mathrm{~cm})$, and plantlet fresh weight $(0.317 \mathrm{~g})$ were obtained when Giza 4 shoots were dipped in $50 \mathrm{mM} \mathrm{L}^{-1} \mathrm{IBA}_{\text {and }}$ cultured in liquid medium (Table 2, Figure 1D). Dipping at $100 \mathrm{mM} \mathrm{L}^{-1} \mathrm{IBA}$ also produced a high rooting percentage (80\%) in a gelled culture; however, the overall growth of chickpea plants was diminished as shoot tip necrosis and yellowing were clearly visible in 50\% plantlets (Figures 1F and 1G). Conversely, a lower abnormality percentage (27\%) of yellowish and/or shoot tip necrosis were observed in shoots cultured in a liquid medium at $50 \mathrm{mM} \mathrm{L}^{-1}$ IBA. Such abnormal symptoms are common in leguminous plants cultured in vitro due to carry over effects of cytokinins (Dewir et al., 2016). Sterilized peat moss showed the lowest rooting percentages of $12 \%$ to $30 \%$ for 50 and $100 \mathrm{mM} \mathrm{L}^{-1}$ IBA, respectively (Figure 1E).

Long incubations are necessary with PGR-free medium to induce rooting; however, root formation is often not observed in all shoots (Singh et al., 2002). Roy et al. (2001) reported that $C$. arietinum shoots rooted after 70-72 d of incubation in rooting medium ( $1 / 2 \mathrm{MS}$ with IBA), but the resultant roots were very small $(0.1-0.2 \mathrm{~cm})$. These roots could not support the plantlets with most plants dying within 3 to $4 \mathrm{~d}$. Hence, there is always a high likelihood of shoot loss due to failures in root development. This low root induction is an additional inadequacy with transgenic legume plants that are already constrained with low transformation efficiency. Additionally, low chickpea transplant survival frequency has been reported (Polisetty et al., 1997; Roy et al., 2001; Huda et al., 2003). Jayanand et al. (2003) described an improved protocol for high-frequency rooting and transplantation frequencies in chickpea; however, this procedure uses three transfer phases that are time consuming. These phases included: (a) rooting using liquid MS medium with $9.4 \mathrm{mM} \mathrm{KNO}_{3}$, $2 \%$ sucrose, and $5 \mu \mathrm{M}$ IBA for $15 \mathrm{~d}$ on filter paper bridges, (b) pulse treatment of un-rooted shoots with $100 \mu \mathrm{M} \mathrm{IBA}$ and subsequent culture on filter paper bridges in liquid MS for $15 \mathrm{~d}$, and (c) transfer to a hypotonic system with $1 / 4$-strength Arnon solution and $3 \mu \mathrm{M}$ IBA for $15-21 \mathrm{~d}$.

In the present study, 93\%-100\% rooting was achieved by dipping the regenerated shoots into $50 \mathrm{mM}$ IBA for $1 \mathrm{~s}$, before culturing them onto a paper bridge liquid MS media without PGRs (Table 3). Chickpea genotypes displayed variations in their rooting to different sucrose levels. Giza 4 recorded $100 \%$ rooting at $40 \mathrm{~g} \mathrm{~L}^{-1}$ sucrose while Giza 88, Giza 195, and Giza 531 recorded the highest rooting (93\%) at $20 \mathrm{~g} \mathrm{~L}^{-1}$ sucrose level. Sucrose levels in the culture medium have been shown to influence in vitro root formation in many leguminous plant species (Dewir et al., 2016). The stimulatory effect of sucrose for in vitro root induction of chickpea was genotype-dependent. High sucrose concentration $\left(45 \mathrm{~g} \mathrm{~L}^{-1}\right)$ favored root induction for Gökçe genotype (Aasim et al., 2013) while low concentration (7.5 g L-1) was optimal for BG-329, BG256, BG-362, BG-267 and C-235 genotypes (Polisetty et al., 1997). In the present study, the occurrence of abnormalities was minimal (27\%-33\%) at low sucrose and IBA concentrations. We were able to reproduce this method for all tested genotypes with all patches tested. Regenerated plantlets were acclimatized with 70\%-75\% survival rates (Figures $1 \mathrm{H}$, 1I, 1J). These results offer a simple and efficient regeneration system for chickpea that can serve as an ideal platform for chickpea transformation and other biotechnological applications. 
Table 2. Effects of indole-3-butyric acid (IBA) and culture type on in vitro rooting of Giza 4 chickpea after 2 wk culture.

\begin{tabular}{llcccc}
\hline $\begin{array}{l}\text { IBA } \\
\text { concentration }\end{array}$ & \multicolumn{1}{c}{ Culture type } & Rooting & Roots & Root length & Fresh weight \\
\hline mmol L $^{-1}$ & & $\%$ & $\mathrm{Nr}^{-}$explant & \\
50 & Gelled & $60 \mathrm{~d}$ & $6.7 \mathrm{~b}$ & $0.7 \mathrm{~b}$ & $0.181 \mathrm{bc}$ \\
& Liquid & $90 \mathrm{a}$ & $27.5 \mathrm{a}$ & $1.3 \mathrm{a}$ & $0.317 \mathrm{a}$ \\
& Sterilized peat moss & $12 \mathrm{f}$ & $6.0 \mathrm{~b}$ & $1.0 \mathrm{ab}$ & $0.051 \mathrm{~d}$ \\
100 & Gelled & $80 \mathrm{~b}$ & $5.0 \mathrm{~b}$ & $0.3 \mathrm{c}$ & $0.151 \mathrm{~cd}$ \\
& Liquid & $70 \mathrm{c}$ & $21.6 \mathrm{a}$ & $0.8 \mathrm{~b}$ & $0.265 \mathrm{ab}$ \\
& Sterilized peat moss & $30 \mathrm{e}$ & $6.3 \mathrm{~b}$ & $1.1 \mathrm{a}$ & $0.059 \mathrm{~d}$ \\
\hline
\end{tabular}

Values followed by the same letter in the same column are nonsignificantly different according to Tukey's test $(\mathrm{P} \leq 0.05)$.

Table 3. Effects of genotype and sucrose concentration on in vitro rooting of chickpea after 2 wk culture.

\begin{tabular}{lccccc}
\hline Genotype & $\begin{array}{c}\text { Sucrose } \\
\text { concentration }\end{array}$ & Rooting & Abnormalities & Roots & Root length \\
\hline \multirow{4}{*}{ Giza 4} & $\mathrm{~g} \mathrm{~L}^{-1}$ & & $\%-$ & Nr explant $^{-1}$ & $\mathrm{~cm} \mathrm{explant}^{-1}$ \\
& 20 & $93 \mathrm{~b}$ & $27 \mathrm{~d}$ & $28 \mathrm{a}$ & $1.8 \mathrm{a}$ \\
\multirow{2}{*}{ Giza 88} & 40 & $100 \mathrm{a}$ & $27 \mathrm{~d}$ & $20 \mathrm{c}$ & $1.1 \mathrm{c}$ \\
& 20 & $93 \mathrm{~b}$ & $27 \mathrm{~d}$ & $19 \mathrm{c}$ & $1.1 \mathrm{c}$ \\
\multirow{2}{*}{ Giza 195} & 40 & $67 \mathrm{c}$ & $33 \mathrm{c}$ & $17 \mathrm{c}$ & $1.0 \mathrm{~d}$ \\
& 20 & $93 \mathrm{~b}$ & $27 \mathrm{~d}$ & $24 \mathrm{~b}$ & $1.7 \mathrm{a}$ \\
\multirow{2}{*}{ Giza 531 } & 40 & $67 \mathrm{c}$ & $40 \mathrm{~b}$ & $18 \mathrm{c}$ & $0.8 \mathrm{~d}$ \\
& 20 & $93 \mathrm{~b}$ & $33 \mathrm{c}$ & $21 \mathrm{c}$ & $1.8 \mathrm{a}$ \\
& 40 & $67 \mathrm{c}$ & $47 \mathrm{a}$ & $17 \mathrm{c}$ & $1.4 \mathrm{~b}$ \\
\hline
\end{tabular}

Values followed by the same letter in the same column are nonsignificantly different according to Tukey's test $(\mathrm{P} \leq 0.05)$.

\section{Synthetic seed formation, conservation, and recovery}

Apical buds from chickpea in vitro shoot cultures were encapsulated in 3\% sodium alginate and hardened with $100 \mathrm{mM}$ $\mathrm{CaCl}_{2}$ to produce synthetic seeds (Figure 2). Both these concentrations of sodium alginate and $\mathrm{CaCl}_{2}$ proved suitable for the synthesis of morphologically round and smooth capsules (Figures 2A and 2B). Similar findings have been reported for other species (Ahmad et al., 2012; Faisal et al., 2012) where 3\% sodium alginate was used with $100 \mathrm{mM} \mathrm{CaCl}{ }_{2}$ for the efficient preparation of seeds. The recovery of synthetic seeds of the four genotypes were examined after 1,2,3, and 5 mo storage (Figure 3). The results showed a high potential for conservation of chickpea using an in vitro synthetic seed approach. After 1 mo conservation on slow growth medium, percentages of recovery were $74.8 \%, 61.9 \%, 85.0 \%$, and $80.0 \%$ for Giza 4, Giza 88, Giza 195, and Giza 531, respectively. The recovery percentages were reduced to $30 \%$ in Giza 4 and Giza 88, whereas Giza 195 and Giza 531 had high recovery percentages of $66.7 \%$ and $70.0 \%$ after 5 mo conservation, respectively. These findings are similar to earlier report by Ozudogru et al. (2011). Recoveries after 2 mo conservation are shown in Figures 2C and 2D.

Slow growth events allow clonal plants to be maintained up to 24 mo under in vitro conditions with periodic subculturing. There are several methods that can maintain slow growth. In most cases, low temperatures combined with a low light intensity or darkness have been used to limit growth. Temperatures in the range of $0-5{ }^{\circ} \mathrm{C}$ are employed with cold-tolerant species. It is also possible to limit growth by modifying the culture medium, mainly by reducing the concentrations of sugars and/or mineral elements, and reducing light and temperature (Rajasekharan and Sahijram, 2015; Muñoz et al., 2019). In general, organized cultures, such as shoots, are used for slow growth storage because undifferentiated tissues, such as callus, are more vulnerable to somaclonal variation (Biswas et al., 2009). A synthetic or artificial seed is defined as an artificially encapsulated somatic embryo, shoot bud or any other meristematic tissue that can be used to functionally mimic a natural seed for sowing and will grow into a plant under in vitro or ex vitro conditions and retain this potential after storage (Rajasekharan and Sahijram, 2015; Rihan et al., 2017). In vitro cultures of various species, including fruit trees (Rai et al., 2009) and ornamental plants (Preece and West, 2009), have been successfully stored for varying periods of time as synthetic seeds consisting of encapsulated shoots. The present study explored the possibility of using in vitro slow growth storage for the medium-term conservation of the chickpea germplasm. The in vitro shoot cultures and synthetic seeds consisting of encapsulated chickpea apical and basal buds were maintained and returned to standard culture conditions after various storage periods to evaluate survival and recovery. Our results showed that synthetic seeds showed a good conservation potential. After 5 mo conservation at $4{ }^{\circ} \mathrm{C}$, the chickpea buds survival rates were $70 \%-75 \%$. The Giza 195 and Giza 531 genotypes were far better for conservation than the other genotypes studied. 
Figure 2. Short-term conservation of chickpea. A-B. Encapsulation. C-D. Recovery of chickpea shoots after 5 mo cold storage.

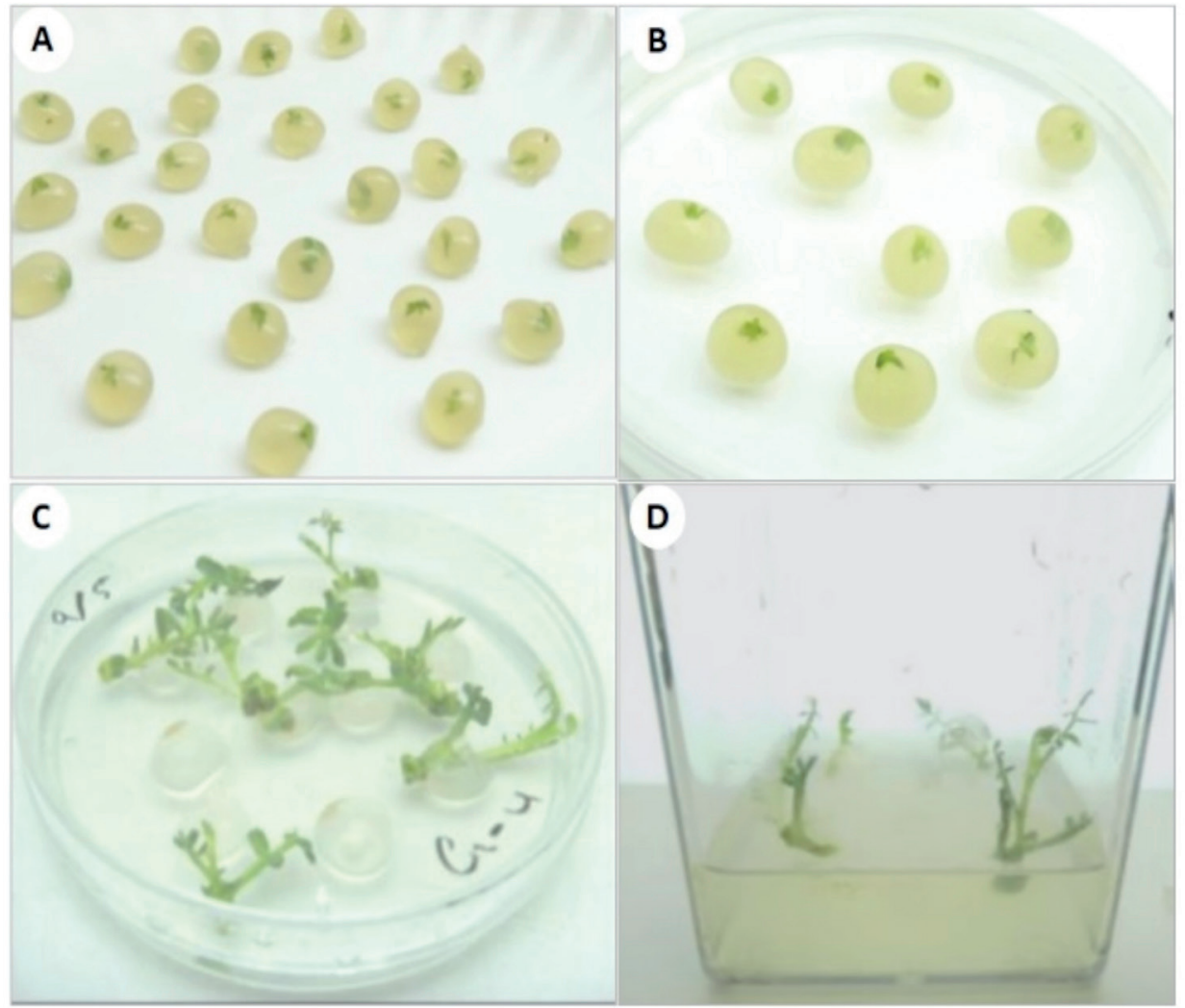

Figure 3. Recovery of synthetic seeds of four chickpea genotypes after 1, 2, 3, and 5 mo cold storage.

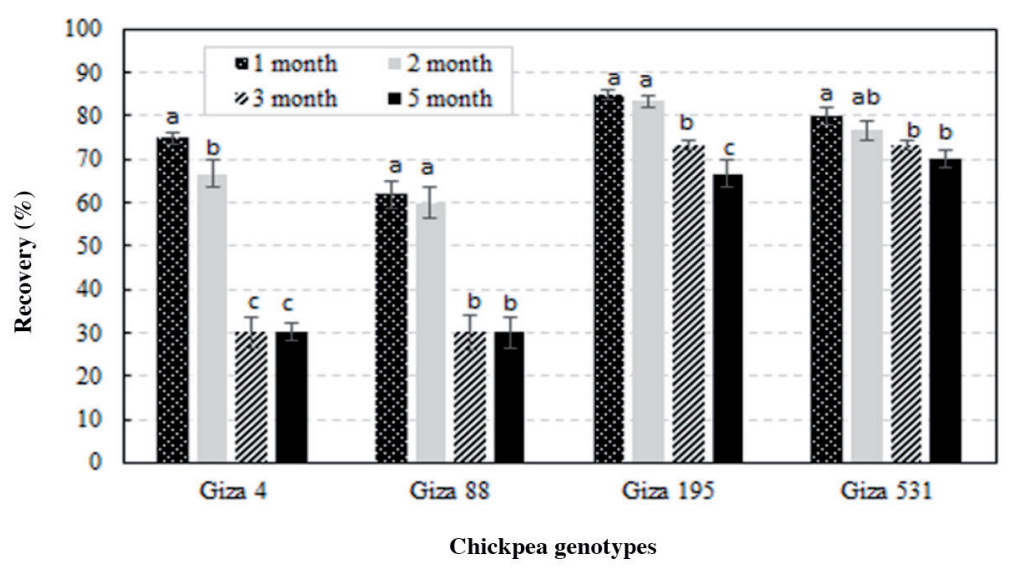

Same letters in the same column group indicate nonsignificantly difference according to Tukey's test $(\mathrm{P} \leq 0.05)$. 


\section{CONCLUSION}

In conclusion, we developed an efficient and simple micropropagation protocol for four chickpea genotypes along with the production of synthetic seeds.

\section{ACKNOWLEDGEMENT}

This project was funded by the National Plan for Science, Technology and Innovation (MAARIFAH), King Abdulaziz City for Science and Technology, Kingdom of Saudi Arabia, Award Number (11-AGR1881-02).

\section{REFERENCES}

Aasim, M., Day, S., Rezaei, F., and Hajyzadeh, M. 2013. Multiple shoot regeneration of plumular apices of chickpea. Turkish Journal of Agriculture and Forestry 37:33-39.

Ahmad, N., Faisal, M., Fatima, N., and Anis, M. 2012. Encapsulation of microcuttings for propagation and short-term preservation in Ruta graveolens L.: a plant with high medicinal value. Acta Physiologiae Plantarum 34:2303-2310.

Ali, S., Khan, S., Shah, S.H., Iqbal, A., Zia, M.A., and Ali, G.M. 2017. Development of efficient regeneration and genetic transformation systems in local cultivars of chickpea (Cicer arietinum L.) Journal of Animal and Plant Sciences 27:2025-2034.

Al-Tanbouz, R., and Abu-Qaoud, H. 2016. In vitro regeneration of chickpea (Cicer arietinum L.) Plant Cell Biotechnology and Molecular Biology 17(1 and 2):21-30.

Amer, A., Mohamed, G., Pantaleo, V., Leonetti, P., and Hanafy, M.S. 2019. In vitro regeneration through organogenesis in Egyptian chickpea. Plant Biosystems 153:835-842.

Anwar, F., Sharmila, P., and Pardha Saradhi, P. 2010. No more recalcitrant: Chickpea regeneration and genetic transformation. African Journal of Biotechnology 9:782-797.

Banu, T., Sarker, R., and Hoque, M. 2011. In vitro plant regeneration of four local varieties of chickpea (Cicer arietinum L.) grown in Bangladesh. Bangladesh Journal of Scientific and Industrial Research 46:379-384.

Biswas, M.K., Dutt, M., Roy, U.K., Islam, R., and Hossain, M. 2019. Development and evaluation of in vitro somaclonal variation in strawberry for improved horticultural traits. Scientia Horticulturae 122:409-416.

Chauhan, R., Tiwari, A., and Singh, N.P. 2003. Differential requirement of mature and immature embryo of chickpea (Cicer arietinum L.) for in vitro regeneration. Indian Journal of Plant Physiology 8:28-33.

Dewir, Y.H., Murthy, H.N., Ammar, M.H., Alghamdi, S.S., Al-Suhaibani, N.A., Alsadon, A.A., et al. 2016. In vitro rooting of leguminous plants: difficulties, alternatives, and strategies for improvement. Horticulture Environment and Biotechnology 57:311-322.

Faisal, M., Alatar, A.A., Ahmad, N., Anis, M., and Hegazy, A.K. 2012. Assessment of genetic fidelity in Rauvolfia serpentina plantlets grown from synthetic (encapsulated) seeds following in vitro storage at $4{ }^{\circ} \mathrm{C}$. Molecules 17:5050-5061.

FAOSTAT Database. 2018. Crops. http://www.fao.org/faostat/en/\#data/QC (accessed on 20 June 2020).

Ghosh, B., and Sen, S. 1994. Plant regeneration from alginate encapsulated somatic embryos of Asparagus cooperi Barker. Plant Cell Reports 13:381-385.

Huda, S., Siddique, N., Khatun, N., Rahman, M., and Morshed, M. 2003. Regeneration of shoot from cotyledon derived callus of chickpea (Cicer arietinum L.) Pakistan Journal of Biological Sciences 6:1310-1313.

Jayanand, B., Sudarsanam, G., and Sharma, K.K. 2003. An efficient protocol for the regeneration of whole plants of chickpea (Cicer arietinum $\mathrm{L}$.) by using axillary meristem explants derived from in vitro germinated seedlings. In Vitro Cellular and Developmental Biology-Plant 39:171-179.

Lambardi, M., Benelli, C., Ozudogru, E.A., and Ozden-Tokatli, Y. 2006. Synthetic seed technology in ornamental plants. p. 347-354. In Teixeira da Silva, J.A. (ed.) Floriculture, ornamental and plant biotechnology: Advances and topical issues. Vol. 2. Global Science Books, Ikenobe, Japan.

Minaei Chenar, H., Kahrizi, D., and Molsaghi, M. 2016. Callus induction is affected by explant type and plant growth regulators in chickpea (Cicer arietinum L.) Biharean Biologist 10:28-32.

Mirakabad, H.Z., Bagheri, A.R., and Zare, M. 2010. Efficient protocol for break impasses of regeneration via callus for 20 genotypes of chickpea. International Journal of Plant Production 4:1735-6814.

Muñoz, M., Díaz, O., Reinún, W., Winkler, A., and Quevedo, R. 2019. Slow growth in vitro culture for conservation of Chilotanum potato germplasm. Chilean Journal of Agricultural Research 79:26-35.

Murashige, T., and Skoog, F. 1962. A revised medium for rapid growth and bioassays with tobacco tissue cultures. Physiologiae Plantarum 15:473-497.

Murthy, B.N.S., Victor, J., Singh, R.P., and Fletcher, R.A. 1996. In vitro regeneration of chickpea (Cicer arietinum L.) stimulation of direct organogenesis and somatic embryogenesis by thidiazuron. Plant Growth Regulation 19:233-240. 
Naz, S., Ali, A., Siddique, F.A., and Iqbal, J. 2008. Somatic embryogenesis from immature cotyledons and leaf calli of chickpea (Cicer arietinum L.) Pakistan Journal of Botany 48:523-531.

Ozudogru, E.A., Kirdok, E., Kaya, E., Capuana, M., De Carlo, E., and Engelmann, F. 2011. Medium-term conservation of redwood (Sequoia sempervirens (D. Don.) Endl.) in vitro shoot cultures and encapsulated buds. Scientia Horticulturae 127:431-435.

Parveen, S., Venkateshwarlu, M., Srinivas, D., Reddy, K.J.M., and Ugandhar, T. 2012. Direct in vitro shoots proliferation of chickpea (Cicer arietinum L.) from shoot tip explants induced by thidiazuron. Bioscience Discovery 3:01-05.

Polisetty, R.,Patil,P., Deveshwar, J.J., Khetarpal, S., Suresh, K., and Chandra, R. 1997. Multiple shoot induction by benzyladenine and complete plant regeneration from seed explants of chickpea (Cicer arietinum L.) Plant Cell Reports 16:565-571.

Preece, J.E., and West, T.P. 2009. Microshoot encapsulation for cold storage, acclimatization, and clean up from arthropod infestations. Acta Horticulturae 812:83-90.

Raghavendra, T., Jayalakshmi, V., and Padmalatha, Y. 2019. An efficient in vitro shoot regeneration protocol from embryo explants of chickpea (Cicer arietinum L.) Legume Research 42:178-181.

Rai, M.K., Asthana, P., Singh, S.K., Jaiswal, V.S., and Jaiswal, U. 2009. The encapsulation technology in fruit plants. A review. Biotechnology Advances 27:671-679.

Rajasekharan, P.E., and Sahijram, L. 2015. In vitro conservation of plant germplasm. p. 417-443. In Bahadur, B., Rajam, M.V., Sahijram, L., and Krishnamurthy, K.V. (eds.) Plant biology and biotechnology. Vol II: Plant genomics and biotechnology. Springer, New Delhi, India.

Reddy, M.C., Murthy, K.S.R., and Pullaiah, T. 2012. Synthetic seeds: A review in agriculture and forestry. African Journal of Biotechnology 11:14254-14275.

Rihan, H.Z., Kareem, F., El-Mahrouk, M.E., and Fuller, M.P. 2017. Artificial seeds (principle, aspects and applications). Agronomy 7:1-15.

Roy, P.K., Lodha, M.L., and Mehta, S.L. 2001. In vitro regeneration from internodal explants and somaclonal variation in chickpea (Cicer arietinum L.) Journal of Plant Biochemistry and Biotechnology 10:107-112.

Singh, R., Srivastava, K., Jaiswal, H., Amla, D., and Singh, B. 2002. High frequency multiple shoot regeneration from decapitated embryo axes of chickpea and establishment of plantlets in the open environment. Biologia Plantarum 45:503-508.

Sunil, S.P., Robinson, J.P., KarthickBalan, S., Anandhaprabhakaran, M., and Balakrishnan, V. 2015. In vitro regeneration and induction of multiple shooting in Cicer arietinum L. using cotyledonary nodal explants. African Journal of Biotechnology 14:1129-1138.

Yadav, S., and Singh, N.P. 2012. An effective protocol for improved regeneration capacity of Kabuli chickpeas. Canadian Journal of Plant Science 92:1057-1064.

Yousefiara, M., Bagheri, A., and Moshtaghi, N. 2008. Optimizing regeneration condition in chickpea. Pakistan Journal of Biological Sciences 11:1009-1014. 